\title{
Efficacy of etanercept on rheumatic signs and pulmonary function tests in advanced ankylosing spondylitis: results of a randomised double-blind placebo-controlled study (SPINE)
}

\author{
M Dougados, ${ }^{1,2}$ J Braun, ${ }^{3}$ S Szanto, ${ }^{4}$ B Combe, ${ }^{5}$ M Elbaz, ${ }^{6}$ P Geher, ${ }^{7}$ G Thabut, ${ }^{8}$ \\ V Leblanc, ${ }^{9}$ | Logeart ${ }^{9}$
}

- Additional data are published online only. To view these files please visit the journal online at (http://ard.bmj.com).

1Paris-Descartes University, UPRES-EA 4058, Paris, France ${ }^{2} \mathrm{APHP}$, Rheumatology B Department, Cochin Hospital Paris, France

${ }^{3}$ Rheumazentrum Ruhrgebiet,

Herne, Germany

${ }^{4}$ University of Debrecen Medical and Health Sciences Center, Debrecen, Hungary

${ }^{5}$ Immuno-Rheumatology Department, Lapeyronie Hospital, Montpellier, France ${ }^{6}$ Medical Center, Avignon, France

${ }^{7}$ Department of Rheumatology, Polyclinic of the Hospitaller Brothers of St John of God Budapest, Hungary

${ }^{8}$ Pneumology Department B, Paris-Diderot University, APHP, Bichat Hospital, Paris France ${ }^{9}$ Pfizer France, Paris la Défense, France

\section{Correspondence to}

Maxime Dougados, Rheumatology B Department, Cochin Hospital, 27 rue du Faubourg Saint Jacques, 75014 Paris, France: maxime.dougados@cch.aphp.fr

Accepted 2 December 2010 Published Online First 13 February 2011

\section{ABSTRACT \\ Objectives Patients with advanced ankylosing} spondylitis (AS) experience disability because of reduced spinal mobility and pulmonary function impairment. This placebo-controlled study evaluated the effect of etanercept (ETN) in patients with advanced AS.

Methods A multicentre randomised double-blind placebo-controlled trial of 12 weeks' duration was performed. Patients had definite (modified New York criteria), active (Bath AS Disease Activity Index (BASDAl) $\geq 40$ ), severe (radiological intervertebral bridges) AS refractory to non-steroidal anti-inflammatory drugs and were antitumour necrosis factor naive. They were treated with ETN 50 mg once weekly or identical placebo (PBO).

Results Of the 95 patients screened, 82 were randomised to receive ETN $(n=39)$ or PBO $(n=43)$. At baseline the disease was active (mean BASDAI $61.0 \pm 13.4$, C reactive protein (CRP) $20.7 \pm 25.5 \mathrm{mg} / \mathrm{l})$ and severe (mean Bath AS Metrology Index (BASMI) $5.7 \pm 1.3$, mSASSS $36.5 \pm 20.5)$; forced pulmonary vital capacity (FVC) was $3.3 \pm 0.7$ I. Improvement in BASDAI (normalised net incremental area under the curve between baseline and week 12, primary end point) was significantly greater in the ETN group than in the PBO group $(-19.8 \pm 16.5$ vs $-11.0 \pm 16.4$, $\mathrm{p}=0.019$ ). Moreover, at week 12, ETN gave better results than $\mathrm{PBO}$ for the BASDAI $(-26.4 \pm 19.7 \mathrm{vs}$ $-14.4 \pm 19.7 ; p=0.008)$, total back pain $(-29.2 \pm 24.0$ vs $-14.9 \pm 24.0 ; p=0.010)$, BASFI $(-21.7 \pm 17.6$ vs $-10.1 \pm 17.6 ; p=0.004)$, BASMI $(-0.6 \pm 0.6$ vs $-0.2 \pm 0.6 ; p=0.011)$, CRP level $(-15.7 \pm 14.2 \mathrm{vs}$ $-1.3 \pm 14.2 ; p<0.001)$ and FVC $(+160 \pm 280 \mathrm{ml} v$ $-20 \pm 280 \mathrm{ml} ; p=0.006$ ).

Conclusions ETN has short-term efficacy for patients with advanced AS, as was previously reported for less advanced disease. The efficacy is observed for the main symptoms (pain) and on markers of inflammation (CRP), as well as disease severity in terms of spinal mobility and pulmonary function.

\section{INTRODUCTION}

The principal concern of patients with ankylosing spondylitis (AS) is progression towards ankylosis and abnormal fixed attitudes (eg, thoracic kyphosis). At the thoracic level, ankylosis is the consequence of ossification of the ligaments and the vertebrocostal and sternocostal joints. ${ }^{1}$ Patients with advanced spinal ankylosis (ie, bamboo spine) experience significantly more functional impairment than do other patients with $\mathrm{AS}^{2}{ }^{2}$ In patients with restricted chest wall motion, airflow measurements are normal but vital capacity (VC) is decreased and functional residual capacity is increased. ${ }^{3-5}$

Tumour necrosis factor (TNF) blockers have greatly improved the condition of patients with active inflammatory spinal disease. ${ }^{6-9}$ Most of these studies excluded patients with total spinal ankylosis. ${ }^{6} 7$

In advanced structural disease (ie, patients with radiological evidence of vertebral fusion at several levels of the spine), the question remains as to whether the symptoms are related to persistent inflammation-which might be reversible after therapy with TNF blockers, for example-or only to the structural ossification process which might be refractory to anti-inflammatory therapy. The issues relate to symptoms (eg, pain, functional disability) and signs (eg, spinal mobility or pulmonary function)

To our knowledge, only three studies have reported the effect of TNF blockers in patients with advanced spinal disease, two of which were observational studies without a control group. ${ }^{10} 11$ The results of these two observational studies suggested improvement of signs and symptoms with treatment in patients with advanced but still active spinal disease, similar to those in whom AS was not advanced. In fact, the single placebo-controlled study of this condition was also a post hoc analysis of adalimumab in a phase III study (eg, ATLAS) evaluating 11 patients with total spinal ankylosis based on assessment of lateral radiographic views of the cervical and lumbar spine. ${ }^{12}$ Clinical response (ie, ASAS20) at week 12 was achieved in three of six patients receiving adalimumab and none of five patients receiving placebo.

Because these studies were weak in methodology (not controlled or performed on small sample size) and because the question was relevant, we initiated a placebo-controlled trial to evaluate the effects of etanercept (ETN) on advanced AS in terms of symptoms (eg, pain and function) and signs (eg, spinal mobility and pulmonary function).

\section{METHODS}

\section{Study design}

This was a 12-week randomised double-blind placebo-controlled multicentre study (clinical trial registration number NCT00420238) conducted in 
21 centres in four European countries (France, Germany, The Netherlands and Hungary) comparing ETN $50 \mathrm{mg}$ subcutaneous injection once weekly, with placebo ( $\mathrm{PBO}$; 1:1 ratio). After a screening period of up to 6 weeks to ensure their eligibility to enter the study, patients were randomised to receive ETN or $\mathrm{PBO}$. Patients were evaluated at screening, baseline and at weeks 2, 4, 8 and 12 .

\section{Patients}

Men and women aged 18-70 years were eligible if they had a current diagnosis of AS as defined by the modified New York criteria. ${ }^{13}$ Patients with AS presented with one of the following three criteria defining advanced and severe spinal ankylosis: (1) two intervertebral adjacent bridges and/or fusion at the lumbar spine; (2) three intervertebral adjacent bridges and/or fusion at the thoracic spine; or (3) two intervertebral adjacent bridges and/or fusion at the cervical spine. Each investigator evaluated the disease at the screening visit from lateral radiographic views of the cervical, thoracic and lumbar spine. Each investigator also evaluated the modified Stoke Ankylosing Spondylitis Spine Score (mSASSS) on radiography. ${ }^{14}$ Finally, from information provided by the investigator, the radiological stage of disease ${ }^{15}$ was determined on a scale of $0-\mathrm{V}$, stages I-III being moderate radiographic evidence of structural damage involving $<50 \%$ of the spine (ie, $\leq 12$ vertebrae) in two spinal segments, and stages IV and $\mathrm{V}$ being advanced AS with stage IV characterised by involvement of $50-80 \%$ of the spine in more than two spinal segments (ie, 13-19 vertebrae) and stage $\mathrm{V}$ by involvement of $\geq 80 \%$ of the spine. Moreover, each investigator checked the radiological evidence of hip involvement from a pelvic x-ray evaluating the BASRIhip scoring system of $0-4$ where 0 is normal, 1 is suspicious (possible focal joint space narrowing), 2 is minimal (definite narrowing, leaving a circumferential joint space $>2 \mathrm{~mm}), 3$ is moderate (narrowing but with circumferential joint space $\leq 2 \mathrm{~mm}$ or bone-on-bone apposition $<2 \mathrm{~cm}$ ) and 4 is severe (bone deformity or bone-on-bone apposition $>2 \mathrm{~cm}$ or total hip replacement). In this report, radiological hip abnormalities (coxitis) are considered as present if observed at either the right or left hip level with a BASRI-hip score of at least 2. ${ }^{16}$ Patients also had to have baseline pain with axial involvement of the overall level of AS neck, back or hip for a score $\geq 30$ on a 0-100 mm visual analogue scale (VAS). Finally, patients had to have an active refractory disease defined by a score $\geq 40$ on the Bath AS Disease Activity Index (BASDAI) $(0-100)^{17}$ despite optimal non-steroidal anti-inflammatory drug (NSAID) treatment (at least two NSAIDs at the maximal tolerated dose for $>3$ months and according to the opinion of the investigator). Patients were excluded from the study if they had been previously exposed to a TNF inhibitor, if the NSAID dose had changed within 2 weeks of baseline evaluation and if the dose of concomitant conventional disease-modifying antirheumatic drug (DMARD; eg, sulfasalazine, methotrexate), if taken, had changed within 4 weeks of baseline evaluation. Patients were also excluded if they had significant concurrent medical disorders (eg, cancer or history of cancer, serious infection) and/or abnormal laboratory test results.

\section{Interventions}

Eligible patients giving informed consent were randomly assigned to receive either ETN $50 \mathrm{mg}$ once weekly or matching placebo. During the 12 weeks of the study the dose of concomitant NSAIDs and any concomitant DMARD had to remain stable. In case of a painful episode during the study, analgesics such as paracetamol, with or without codeine or dextropropoxyphen, could be used.

\section{Outcome measures}

Patients were evaluated at screening, baseline and weeks 2, 4, 8 and 12 .

At each visit, disease was assessed by the Patient Global Assessment (PGA) (0-100 VAS), the BASDAI, ${ }^{17}$ the Bath Ankylosing Spondylitis Functional Index (BASFI), ${ }^{18}$ the Bath AS Metrology Index (BASMI) ${ }^{19} 20$ and $C$ reactive protein (CRP) level. Two further end points evaluated by the patients were the Minimum Clinically Important Improvement (MCII ${ }^{21}$ and Patient Acceptable Symptom State (PASS) ${ }^{22}$ from weeks 2 to 12. The MCII consists of two questions aimed at defining whether the observed difference (eg, less pain) from baseline constitutes a trivial or an important improvement to patients, and the PASS consists of one question aimed at defining whether the observed changes lead to an acceptable symptom state according to the patient.

At weeks 0 and 12, pulmonary function tests (eg, VC, forced vital capacity (FVC), forced expiratory volume in $1 \mathrm{~s}\left(\mathrm{FEV}_{1}\right)$ and the ratio $\left(\mathrm{FEV}_{1} / \mathrm{FVC}\right)$ ) were locally performed in accordance with American Thoracic Society standards. Predicted values were obtained from European recommendations. ${ }^{23}$

\section{Sample size calculation}

The planned sample size of 40 patients per group was sufficient to show a difference of 15 points for the primary end point (expected difference between groups in the normalised net incremental area under the curve for BASDAI) assuming a SD of 20. This sample size was based on a power of $90 \%$ and a twosided type 1 error of $5 \%$.

\section{Statistical analysis}

The primary end point (eg, normalised net incremental area under the curve (AUC) in the BASDAI between randomisation (baseline) and week 12) was calculated as the area between baseline and the PGA curve as a function of time, using the linear trapezoidal method, divided by the number of days the patient remained in the study. It was analysed by an analysis of variance (ANCOVA) method with treatment as a factor and BASDAI baseline as a covariate.

A mixed model ANCOVA with an autoregressive correlation structure with treatment groups, visits and their interaction as fixed factors and baseline scores as a covariate was also used to analyse changes from baseline in the BASDAI and other continuous secondary efficacy variables such as the ASDAS. ${ }^{24}$ For binary efficacy variables (ASAS20, ASAS40, ASAS5/6, ASAS partial remission, and improvement in BASDAI of at least $50 \%$ (BASDAI50), improvement in AS-DAS and AS-DAS status) $)^{25-27}$ a generalised estimating equation model with a logit link, a binominal distribution and an autoregressive correlation structure was used, with treatment groups, visits and their interaction as fixed factors. The primary analysis was modified intent-to-treat, which included all randomised subjects who received at least one blinded dose of test article, with the last observation carried forward used for missing values.

The time to achieve a sustained acceptable symptom state by the PASS was estimated by the Kaplan-Meier method. The two survival curves were compared by the log-rank test. 


\section{RESULTS}

\section{Patients and study course}

Of the 95 screened patients, 82 were eligible for randomisation in the study. The mean reasons for exclusion were low level of active disease (eg, BASDAI <40) or withdrawal of consent. Of the 82 enrolled patients, 39 received treatment with ETN and 43 $\mathrm{PBO}$. The two groups did not differ significantly in demographic characteristics, symptomatic activity or severity of disease at baseline (table 1).

Figure 1 illustrates the flow of patients during the study. Five patients dropped out of the study after randomisation: one patient in the ETN group after the first injection following a detailed evaluation of a chest x-ray performed at screening which revealed a pre-existing lung neoplasm, four patients in the $\mathrm{PBO}$ group because of lack of efficacy for two, withdrawal of consent for one and lost to follow-up for one.

\section{Efficacy}

The mean \pm SD normalised net incremental AUC for the BASDAI (primary efficacy end point) during the 12 weeks of treatment was significantly greater for the ETN group than for the PBO group $(-11 \pm 16$ vs $-20 \pm 17 ; \mathrm{p}=0.019)$.

The ETN group showed significantly better results than the $\mathrm{PBO}$ group for the responder criteria ASAS20 and ASAS5/6 and for BASDAI50 but not ASAS40 and ASAS partial remission (table 2).

Absolute changes between baseline and week 12 showed a statistically significant difference favouring ETN (table 3).
Moreover, at week 12, according to the MCII, significantly more patients in the ETN group were improved than in the $\mathrm{PBO}$ group, with $24(63 \%)$ versus $14(38 \%)$ patients showing very or moderately improved scores $(p=0.025)$; according to the PASS, 23 (61\%) versus 15 (41\%) ETN- and placebo-treated patients, respectively, considered their condition as acceptable $(\mathrm{p}=0.065)$.

The onset of action of the treatment was quick, as the changes in BASDAI over time showed a significant difference between groups in favour of etanercept from week $8(-26.1 \pm 19.8$ vs $-13.6 \pm 19.7 ; p=0.005)$ and sustained until week $12(-26.4 \pm 19.8$ vs $-14.4 \pm 19.7 ; p=0.008$ ) (figure 2 ). Nine of 43 patients in the $\mathrm{PBO}$ group and 22 of 39 patients in the ETN group reported a sustained PASS over the 12 weeks. The median time to reach this status was 8 weeks (95\% CI 3.9, NA) for the ETN group but could not be evaluated in the $\mathrm{PBO}$ group because fewer than $50 \%$ of the patients experienced a sustained response $(p=0.0009$, log-rank test).

The ETN group therefore achieved quick onset of action (as early as week 2), with a statistically significant difference between the two groups from week 8 .

There was a trend in favor of ETN for all the clinically evaluated parameters. Concerning spinal mobility measures, the responsiveness of the different components of the BASMI and also the chest expansion are shown in table S1 in the online supplement. These results suggest that the most responsive component is the spinal lateral flexion, but only the changes in the composite index reached the intergroup statistical significance.

Table 1 Patient demographics and disease characteristics at baseline by treatment group

\begin{tabular}{|c|c|c|c|}
\hline \multirow[b]{2}{*}{ Characteristics } & \multicolumn{2}{|l|}{ Treatment group } & \multirow[b]{2}{*}{ All $(n=82)$} \\
\hline & Placebo $(n=43)$ & Etanercept $(n=39)$ & \\
\hline Age, years & $48 \pm 10$ & $46 \pm 11$ & $47 \pm 10$ \\
\hline Men, $\mathrm{n}(\%)$ & $39(91 \%)$ & $37(95 \%)$ & $76(93 \%)$ \\
\hline Disease duration, years & $23 \pm 11$ & $19 \pm 10$ & $21 \pm 11$ \\
\hline HLA B27 positive, n (\%) & $36(86 \%)$ & $31(79 \%)$ & $67(83 \%)$ \\
\hline \multicolumn{4}{|l|}{ Past history or present symptoms, $\mathrm{n}(\%)$} \\
\hline Peripheral arthritis & $19(44 \%)$ & $18(46 \%)$ & $37(45 \%)$ \\
\hline Enthesiopathy & $18(42 \%)$ & $11(28 \%)$ & $29(35 \%)$ \\
\hline Uveitis & $12(28 \%)$ & $13(33 \%)$ & $25(30 \%)$ \\
\hline Psoriasis & $5(12 \%)$ & $4(10 \%)$ & $9(11 \%)$ \\
\hline \multicolumn{4}{|l|}{ Spinal radiological stage, $\mathrm{n}(\%)$} \\
\hline ॥ & $3(7 \%)$ & $7(18 \%)$ & $10(12 \%)$ \\
\hline III & $26(60 \%)$ & $21(54 \%)$ & $47(57 \%)$ \\
\hline IV & $9(21 \%)$ & $7(18 \%)$ & $16(20 \%)$ \\
\hline V & $5(12 \%)$ & $4(10 \%)$ & $9(11 \%)$ \\
\hline Intervertebral radiological fusion (0-24) & $10 \pm 6$ & $9 \pm 6$ & $10 \pm 6$ \\
\hline Radiological mSASSS (0-72) & $39 \pm 19$ & $34 \pm 22$ & $37 \pm 21$ \\
\hline Radiological hip abnormalities (coxitis) ${ }^{*}$ & $14(35 \%)$ & $12(32 \%)$ & $26(33 \%)$ \\
\hline BASDAI $(0-100)$ & $58 \pm 15$ & $64 \pm 12$ & $61 \pm 13$ \\
\hline BASFI (0-100) & $57 \pm 19$ & $63 \pm 20$ & $60 \pm 19$ \\
\hline BASMI (0-10) & $5.8 \pm 1.3$ & $5.7 \pm 1.4$ & $57 \pm 1.3$ \\
\hline Total back pain $(0-100)$ & $61 \pm 20$ & $70 \pm 16$ & $65( \pm 19$ \\
\hline CRP level, mg/l & $17 \pm 19$ & $25 \pm 31$ & $21 \pm 26$ \\
\hline ASDAS-CRP & $3.63 \pm 0.76$ & $3.90 \pm 0.71$ & $3.76 \pm 0.75$ \\
\hline \multicolumn{4}{|l|}{ Disease activity state, $\mathrm{n}(\%)$} \\
\hline ASDAS-CRP $<1.3$ (inactive disease) & $0(0)$ & $0(0)$ & $0(0)$ \\
\hline ASDAS-CRP $>1.3-<2.1$ (moderate disease activity) & $1(2.4)$ & $0(0)$ & $1(1.3)$ \\
\hline ASDAS-CRP $>2.1-<3.5$ (high disease activity) & $17(41.5)$ & $12(30.8)$ & $29(36.3)$ \\
\hline ASDAS-CRP $\geq 3.5$ (very high disease activity) & $23(56.1)$ & $27(69.2)$ & $50(62.5)$ \\
\hline
\end{tabular}


There was also a trend in favor of ETN for all the evaluated pulmonary tests and, in particular, at the end of the 12-week study, there was a lower percentage of patients with a pulmonary restrictive pattern. The results related to pulmonary function tests are shown in table 4.

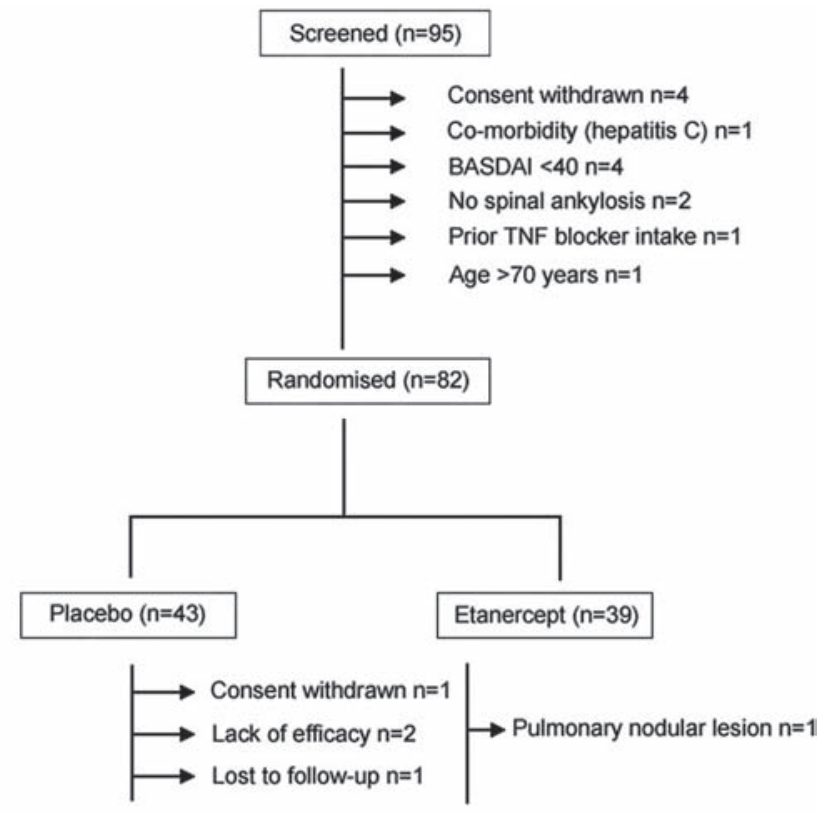

Placebo completers $(n=39)$

Etanercept completers $(n=38)$

Figure 1 Flow of patients through the trial.

Table 2 Responder criteria after 12 weeks of therapy by treatment group

\begin{tabular}{lccr}
\hline & \multicolumn{2}{l}{ Treatment group } & \\
\cline { 2 - 3 } Responder criteria & $\begin{array}{l}\text { Placebo } \\
(\mathbf{n}=\mathbf{4 3})\end{array}$ & $\begin{array}{l}\text { Etanercept } \\
(\mathbf{n}=\mathbf{3 9})\end{array}$ & p Value \\
\hline ASAS20 & $14(33 \%)$ & $25(67 \%)$ & 0.003 \\
ASAS40 & $10(23 \%)$ & $17(44 \%)$ & 0.053 \\
ASAS5/6 & $2(5 \%)$ & $8(21 \%)$ & 0.044 \\
ASAS partial remission & $2(5 \%)$ & $7(18 \%)$ & 0.073 \\
BASDAI 50 & $10(23 \%)$ & $18(46 \%)$ & 0.031 \\
ASDAS-CRP changes (W12-baseline) & & & \\
$\quad$ ASDAS $\geq 1.1$ (minimally important & $7(17.1)$ & $25(64.1)$ & $<0.0001$ \\
$\begin{array}{l}\text { improvement) } \\
\quad \text { ASDAS } \geq 2.0 \text { (major improvement) }\end{array}$ & $1(2.4)$ & $15(38.5)$ & $<0.0001$ \\
ASDAS-CRP status at W12 & & & \\
$\quad$ ASDAS $<1.3$ & $35(85.4)$ & $17(43.6)$ & $<0.001$ \\
$\quad$ ASDAS $<2.1$ & $41(100)$ & $25(64.1)$ & $<0.0001$ \\
\hline
\end{tabular}

ASAS, Ankylosing Spondylitis Activity Score; ASDAS, Ankylosing Spondylitis Disease Activity Score; BASDAl, Bath Ankylosing Spondylitis Disease Activity Index.

\section{Safety}

Overall, no unexpected adverse events or changes in laboratory values or vital signs were observed that gave cause for concern. A total of 28 patients in the $\mathrm{PBO}$ group (65\%) and 24 patients in the ETN group (62\%) experienced at least one adverse event.

Three patients were considered by the investigator to have a serious adverse event: one patient in the ETN group was diagnosed with a lung neoplasm after detailed evaluation of the chest x-rays performed at screening (this patient withdrew from the study at the time of the diagnosis, ie, after the first injection), one patient in the ETN group experienced a fluctuating mild to moderate asymptomatic neutropenia during the entire study, and one patient in the $\mathrm{PBO}$ group experienced aggravated AS which resulted in his withdrawal from the study at week 8. Adverse events occurred in at least $5 \%$ of patients; injection site reaction was the most frequent with three patients $(8 \%)$ in the ETN group and none in the PBO group.

\section{DISCUSSION}

This study of AS patients with advanced spinal damage seen on x-rays demonstrates the short-term symptomatic efficacy of ETN over $\mathrm{PBO}$ but also suggests that, despite such spinal ankylosis, ETN might improve spinal mobility and respiratory function.

The strengths of the study are its well-defined inclusion criteria, a $\mathrm{PBO}$-controlled group and an a priori chosen primary end point to evaluate the short-term efficacy of ETN in symptoms of advanced AS. One of the difficulties in designing the trial was to define clearly the radiological criteria for 'advanced disease'. On the basis of the personal experience of the scientific committee in charge of the design of the protocol, the presence of intervertebral adjacent bridges (at least two at the lumbar or cervical spine level or three at the thoracic level) was considered advanced disease. A post hoc analysis of data collected by the local investigator allowed for categorising disease according to the radiological grade scale from I to IV. ${ }^{15}$ Moreover, the mean mSASSS score we observed at baseline in the modified intentto-treat population $(36.5 \pm 20.5)$ was higher than the score from 'conventional' studies evaluating the structural effect of TNF blockers $\left(16 \pm 18,18 \pm 18,20 \pm 19\right.$ in the ETN, ${ }^{28}$ infliximab ${ }^{29}$ and adalimumab ${ }^{30}$ trials, respectively). In addition, the percentage of patients with a coxitis (eg, radiological hip abnormalities) was greater in the study population (eg, 33\%), also reflecting severe disease. The observed BASMI for spinal mobility at baseline was higher than that reported in previous studies $(5.7 \pm 1.4$ vs $3.7 \pm 2.2$ and $3.4 \pm 2.2$ for etanercept and sulfasalazine baseline values in the ASCEND trial and $4.2 \pm 2.1$ and $3.8 \pm 2.2$ for adalimumab and placebo baseline values in the ATLAS trial). ${ }^{8} 31$ These findings confirm the 'advanced' disease characteristic of our enrolled

Table 3 Absolute changes between baseline and week 12 in parameters by treatment group

\begin{tabular}{|c|c|c|c|c|c|c|c|}
\hline \multirow[b]{2}{*}{ Parameter } & \multicolumn{2}{|l|}{ Baseline (week 0) } & \multicolumn{2}{|l|}{ Week 12} & \multicolumn{2}{|c|}{ Adjusted changes (week 12-week 0) } & \multirow[b]{2}{*}{$\mathrm{p}$ Value } \\
\hline & Placebo* $(n=43)$ & Etanercept* $(n=39)$ & Placebo* $^{*}(n=43)$ & Etanercept* $(n=39)$ & Placebot $(n=43)$ & Etanercept† $(n=39)$ & \\
\hline$\overline{\text { BASDAI }(0-100)}$ & $58 \pm 15$ & $64 \pm 12$ & $45 \pm 19$ & $37 \pm 26$ & $-14 \pm 20$ & $-26 \pm 20$ & 0.008 \\
\hline BASFI (0-100) & $57 \pm 19$ & $63 \pm 20$ & $48 \pm 21$ & $41 \pm 29$ & $-10 \pm 18$ & $-22 \pm 18$ & 0.004 \\
\hline Total back pain, $(0-100)$ & $61 \pm 20$ & $70 \pm 16$ & $48 \pm 22$ & $38 \pm 28$ & $-15 \pm 24$ & $-29 \pm 24$ & 0.010 \\
\hline $\mathrm{CRP}, \mathrm{mg} / \mathrm{l}$ & $17 \pm 19$ & $25 \pm 31$ & $18 \pm 20$ & $6 \pm 8$ & $-1 \pm 14$ & $-16 \pm 14$ & $<0.0001$ \\
\hline ASDAS-CRP & $3.63 \pm 0.76$ & $3.90 \pm 0.71$ & $3.18 \pm 0.95$ & $2.3 \pm 0.97$ & $-0.49 \pm 0.87$ & $-1.51 \pm 0.87$ & $<0.0001$ \\
\hline
\end{tabular}

*Data are mean \pm SD.

tData are adjusted mean \pm SD from a mixed model ANCOVA with an autoregressive correlation structure with treatment groups, visits and their interaction as fixed factors and baseline scores as a covariate.

ASDAS-CRP, Ankylosing Spondylitis Disease Activity Score-CRP; BASDAl, Bath Ankylosing Spondylitis Disease Activity Index; BASFI, Bath Ankylosing Spondylitis Functional Index; BASMI, Bath Ankylosing Spondylitis Metrology Index; CRP, C reactive protein. 


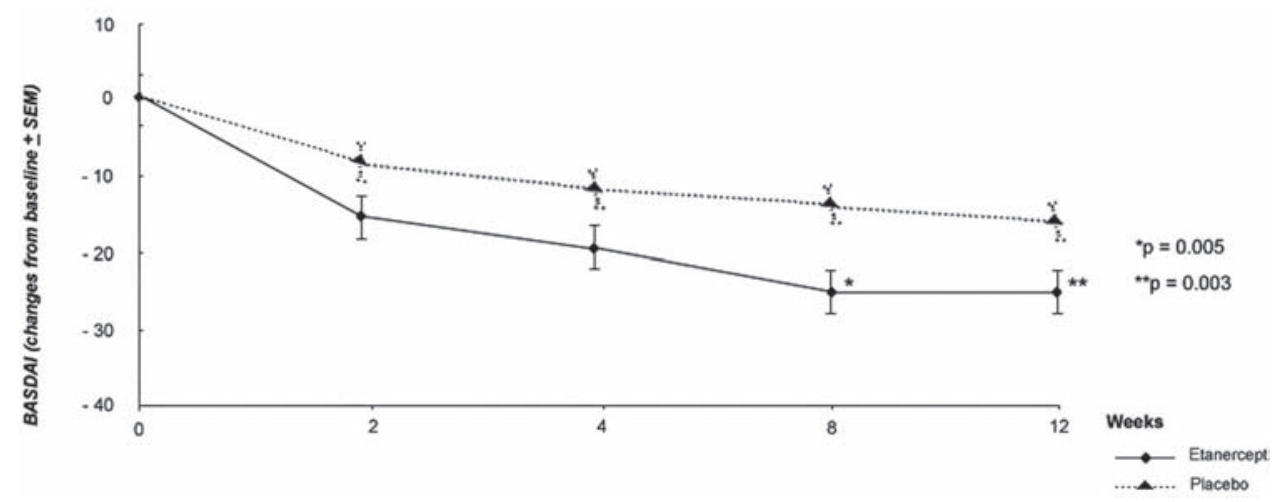

Figure 2 Absolute changes in Bath Ankylosing Spondylitis Disease Activity Index (BASDAI) from baseline during the 12 weeks of the study by treatment group (etanercept vs placebo).

Table 4 Changes in pulmonary function during the 12 weeks of the study by treatment group

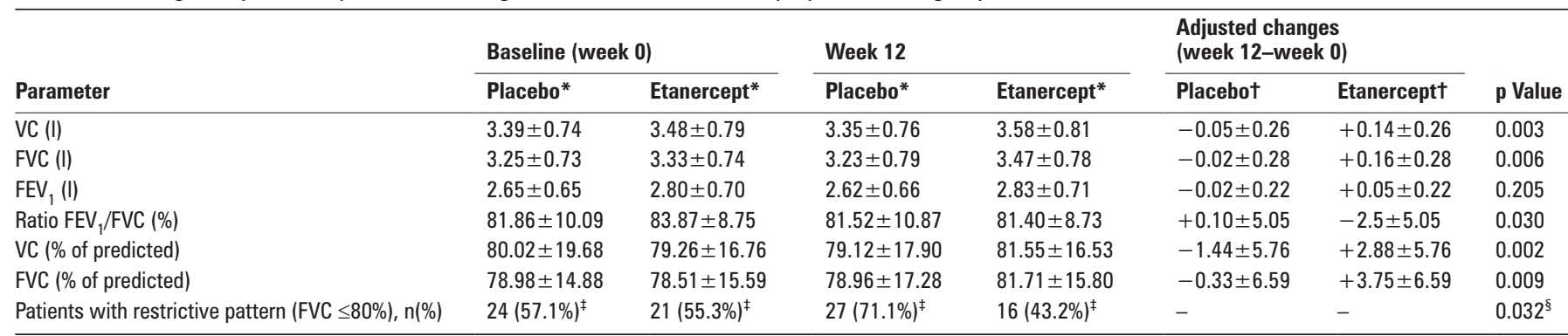

\footnotetext{
*Data are mean \pm SD.

${ }^{\dagger}$ Data are adjusted mean \pm SD from a mixed model ANCOVA with an autoregressive correlation structure with treatment groups, visits and their interaction as fixed factors and baseline scores as a covariate.

‡Data are number (\%) of patients.

${ }^{\S}$ Statistically significant (Fisher exact test).

$\mathrm{FEV}_{1}$, forced expiratory volume in 1 second; FVC, forced vital capacity; VC, vital capacity.
}

patients. Besides this structural severity, patients had active disease at baseline as determined by both the BASDAI $(61 \pm 13)$ and CRP level $(21 \pm 26 \mathrm{mg} / \mathrm{l})$, which were similar to values from clinical trials evaluating TNF blockers $(61 \pm 15$ and $20 \pm 21 \mathrm{mg} / \mathrm{l}$ in the ETN trial ${ }^{6}$ and $63 \pm 17$ and $21 \pm 27 \mathrm{mg} / 1$ in the adalimumab trial). ${ }^{8}$

ETN gave statistically significant higher values for most variables of efficacy. In addition, these results confirm the higher discriminant capacity of ASDAS-CRP compared with the conventional BASDAI score. ${ }^{32}$ Indeed, we observed the highest statistically significant intergroup difference for the ASDAS-CRP parameter. The magnitude of the effect in terms of change in status (eg, ASAS20 responder criteria: $67 \%$ vs $33 \%$ in the ETN vs placebo group) was similar to that observed in clinical trials evaluating TNF blockers in patients with active AS but less advanced disease. The main difference is from results evaluating the status at the end of the trial in terms of spinal mobility or functional impairment-for example, in our study the BASFI score decreased from 63 to 41 after ETN therapy (ie, a clinically relevant change but still residual relevant functional disability), whereas in the previous trials of ETN in patients with less advanced disease the BASFI score decreased from 61 to 32 after 12 weeks of therapy. ${ }^{33}$ Such findings suggest that TNF blockers are still of use for patients with active advanced disease but, also for this condition, a 'floor' effect can be observed because of the underlying structural damage. This finding suggests initiation of treatment at an early stage of the disease. ${ }^{34}$

The results observed in pulmonary function are also interesting. Most of the patients exhibited a typical restrictive pattern at baseline (FVC $\geq 80 \%$, commonly used to assess restrictive pulmonary defect). One previous study has shown that this pattern is a consequence of reduced mobility of the thoracic cage. $^{3}$ To our knowledge, this study is the first to evaluate systematically the treatment effect of TNF blockers on these parameters. ${ }^{35}$ The significant improvement in FVC of $160 \mathrm{ml}$ observed in the ETN group compared with a decrease of $20 \mathrm{ml}$ in the $\mathrm{PBO}$ group after 12 weeks is encouraging and should be interpreted in the light of the short treatment period.

The relatively short time period of our study could be considered a limitation. However, the rapid onset of action and the sustainability of the response with ETN demonstrate its symptomatic efficacy.

Although the study was not designed to assess the potential toxicity of ETN, we observed no unexpected adverse events.

In summary, this is the first prospective randomised placebo-controlled study specifically designed to evaluate ETN in advanced active AS disease; it demonstrates a symptomatic clinically relevant and statistically significant benefit. The next step will be to determine the optimal management for this population in the long term.

Acknowledgements The authors are grateful to RCTS Company, Lyon, France, for monitoring of French centers, data management and statistical analysis of the study. The authors thank Carla Carvalho (Wyeth) and Florence Masson for their contributions to operational management of the study. They thank the investigators, staff and patients for participation in this clinical trial.

Funding This study was sponsored by Wyeth Pharmaceuticals (Wyeth was acquired by Pfizer in October 2009).

Competing interests MD: Pfizer Inc (consulting fees, speakers' bureau). JB Pfizer Inc (consulting fees). SS: Pfizer Inc (consulting fees). BC: Pfizer Inc (research grants, consulting fees, speakers' bureau); Schering (research grants, consulting fees, speakers' bureau); UCB Inc (research grants, consulting fees). ME: Pfizer Inc (consulting fees). PG: Abbott Laboratories (consulting fees); Pfizer Inc (consulting 
fees); Schering-Plough (consulting fees). GT: Pfizer Inc (consulting fees). VL: Pfizer Inc (employment). IL: Pfizer Inc (employment).

Patient consent Obtained.

Contributors MD was the principal investigator for the study. The authors and the study investigators gathered the data and interpreted the data. IL was a medical monitor during the trial. MD and IL designed the trial, interpreted the data and wrote the report. $V L$ interpreted the data, wrote the report and served as medical monitor during the trial. Vincent Haudiquet (Wyeth) supervised statistical analysis. All authors reviewed and approved the report before submission. MD had full access to all of the data and had final responsibility for the decision to submit the manuscript for publication.

Ethics approval The trial was conducted in accordance with the ethical principles of the Declaration of Helsinki and was consistent with the guidelines for Good Clinical Practices ICH-E6 and regulations. The study protocol and informed consent document were approved by each institution's review board or independent ethics committee.

Provenance and peer review Not commissioned; externally peer reviewed.

\section{REFERENCES}

1. Dougados M, Landewé R. Spondyloarthritides: pathogenesis, clinical aspect and diagnosis. In: Bijlsma J, ed. EULAR Compendium on Rheumatic Diseases. London: BMJ Publishing Group 2009:92-116.

2. Boonen $\mathbf{A}$, van der Linden SM. The burden of ankylosing spondylitis. J Rheumatol Supp/ 2006; $78: 4-11$

3. Feltelius $\mathbf{N}$, Hedenström $\mathrm{H}$, Hillerdal G, et al. Pulmonary involvement in ankylosing spondylitis. Ann Rheum Dis 1986;45:736-40.

4. Sampaio-Barros PD, Cerqueira EM, Rezende SM, et al. Pulmonary involvement in ankylosing spondylitis. Clin Rheumatol 2007;26:225-30.

5. Fisher LR, Cawley MI, Holgate ST. Relation between chest expansion, pulmonary function, and exercise tolerance in patients with ankylosing spondylitis. Ann Rheum Dis 1990:49:921-5.

6. Davis JC Jr, Van Der Heijde D, Braun J, et al. Recombinant human tumor necrosis factor receptor (etanercept) for treating ankylosing spondylitis: a randomized, controlled trial. Arthritis Rheum 2003;48:3230-6.

7. van der Heijde D, Dijkmans B, Geusens $P$, et al. Efficacy and safety of infliximab in patients with ankylosing spondylitis: results of a randomized, placebo-controlled trial (ASSERT). Arthritis Rheum 2005;52:582-91.

8. van der Heijde D, Kivitz A, Schiff MH, et al. Efficacy and safety of adalimumab in patients with ankylosing spondylitis: results of a multicenter, randomized, doubleblind, placebo-controlled trial. Arthritis Rheum 2006:54:2136-46.

9. Heiberg MS, Nordvåg BY, Mikkelsen K, et al. The comparative effectiveness of tumor necrosis factor-blocking agents in patients with rheumatoid arthritis and patients with ankylosing spondylitis: a six-month, longitudinal, observational, multicenter study. Arthritis Rheum 2005;52:2506-12.

10. Cheung PP, Tymms KE, Wilson BJ, et al. Infliximab in severe active ankylosing spondylitis with spinal ankylosis. Intern Med J 2008;38:396-401.

11. Rudwaleit M, Olivieri I, Boki KA, et al. Adalimumab is effective and well tolerated in treating patients with ankylosing spondylitis who have advanced spinal fusion. Rheumatology (Oxford) 2009; 48:551-7.

12. van der Heijde D, Pangan AL, Schiff MH, et al.; ATLAS Study Group. Adalimumab effectively reduces the signs and symptoms of active ankylosing spondylitis in patients with total spinal ankylosis. Ann Rheum Dis 2008;67:1218-21.

13. van der Linden $\mathbf{S}$, Valkenburg HA, Cats A. Evaluation of diagnostic criteria for ankylosing spondylitis. A proposal for modification of the New York criteria. Arthritis Rheum 1984;27:361-8.

14. van der Heijde D, Landewé R. Selection of a method for scoring radiographs for ankylosing spondylitis clinical trials, by the Assessment in Ankylosing Spondylitis Working Group and OMERACT. J Rheumatol 2005;32:2048-9.
15. Braun J, van der Heijde, Dougados M, et al. Staging of patients with ankylosing spondylitis. Ann Rheum Dis 2002;61 (Suppl III):iii19-23.

16. MacKay K, Brophy S, Mack C, et al. The development and validation of a radiographic grading system for the hip in ankylosing spondylitis: the Bath Ankylosing Spondylitis Radiology Hip Index. J Rheumatol 2000;27:2866-72.

17. Garrett S, Jenkinson T, Kennedy LG, et al. A new approach to defining disease status in ankylosing spondylitis: the Bath Ankylosing Spondylitis Disease Activity Index. J Rheumatol 1994;21:2286-91.

18. Calin A, Garrett $\mathrm{S}$, Whitelock $\mathrm{H}$, et al. A new approach to defining functional ability in ankylosing spondylitis: the development of the Bath Ankylosing Spondylitis Functional Index. J Rheumatol 1994;21:2281-5.

19. Jenkinson TR, Mallorie PA, Whitelock HC, et al. Defining spinal mobility in ankylosing spondylitis (AS). The Bath AS Metrology Index. J Rheumatol 1994;21:1694-8.

20. van der Heijde $\mathbf{D}$, Landewé $\mathrm{R}$, Feldtkeller E. Proposal of a linear definition of the Bath Ankylosing Spondylitis Metrology Index (BASMI) and comparison with the 2-step and 10-step definitions. Ann Rheum Dis 2008;67:489-93.

21. Tubach F, Ravaud P, Baron G, et al. Evaluation of clinically relevant changes in patient reported outcomes in knee and hip osteoarthritis: the minimal clinically important improvement. Ann Rheum Dis 2005;64:29-33.

22. Tubach F, Ravaud P, Baron G, et al. Evaluation of clinically relevant states in patient reported outcomes in knee and hip osteoarthritis: the patient acceptable symptom state. Ann Rheum Dis 2005:64:34-7.

23. Anon. Seconde édition française des recommandations européennes pour les explorations fonctionnelles respiratiores. Rev Mal Respir 2001;18:6S7-6S119.

24. Lukas C, Landewé R, Sieper J, et al. Development of an ASAS-endorsed disease activity score (ASDAS) in patients with ankylosing spondylitis. Ann Rheum Dis 2009;68:18-24.

25. Anderson JJ, Baron G, van der Heijde D, et al. Ankylosing spondylitis assessment group preliminary definition of short-term improvement in ankylosing spondylitis. Arthritis Rheum 2001;44:1876-86.

26. Machado $\mathbf{P}$, Landewé $\mathrm{R}$, Lie $\mathrm{E}$, et al. Ankylosing spondylitis disease activity score (ASDAS): defining criteria for disease activity states and improvement scores. Ann Rheum Dis 2010;69(Suppl 3):0P0131.

27. Brandt J, Listing J, Sieper J, et al. Development and preselection of criteria for short term improvement after anti-TNF alpha treatment in ankylosing spondylitis. Ann Rheum Dis 2004;63:1438-44.

28. van der Heijde $\mathbf{D}$, Landewé $\mathrm{R}$, Einstein $\mathrm{S}$, et al. Radiographic progression of ankylosing spondylitis after up to two years of treatment with etanercept. Arthritis Rheum 2008;58:1324-31.

29. van der Heijde D, Landewé R, Baraliakos X, et al. Radiographic findings following two years of infliximab therapy in patients with ankylosing spondylitis. Arthritis Rheum 2008:58:3063-70.

30. van der Heijde D, Salonen D, Weissman BN, et al. Assessment of radiographic progression in the spines of patients with ankylosing spondylitis treated with adalimumab for up to 2 years. Arthritis Res Ther 2009;11:R127.

31. Braun J, Huang F, Burgos-Vargas R, et al. Assessment of clinical efficacy in a randomized, double-blind study of etanercept and sulphasalazine in patients with ankylosing spondylitis. Arthritis Rheum 2008;58(Suppl 9):S415(673).

32. van der Heijde D, Lie E, Kvien TK, et al. ASDAS, a highly discriminatory ASAS-endorsed disease activity score in patients with ankylosing spondylitis. Ann Rheum Dis 2009;68:1811-8.

33. van der Heijde D, Da Silva JC, Dougados M, et al. Etanercept $50 \mathrm{mg}$ once weekly is as effective as $25 \mathrm{mg}$ twice weekly in patients with ankylosing spondylitis. Ann Rheum Dis 2006;65:1572-7.

34. Sieper J, Rudwaleit M. How early should ankylosing spondylitis be treated with tumour necrosis factor blockers? Ann Rheum Dis 2005;64(Suppl 4):iv61-4.

35. Quismorio FP Jr. Pulmonary involvement in ankylosing spondylitis. Curr Opin Pulm Med 2006;12:342-5. 


\section{Corrections}

M Dougados, J Braun, S Szanto, et al. Efficacy of etanercept on rheumatic signs and pulmonary function tests in advanced ankylosing spondylitis: results of a randomised double-blind placebocontrolled study (SPINE). Ann Rheum Dis 2011;70:799-804 doi:10.1136/ard.2010.139261. The data published for ASDAS-CRP status at W12 in Table 2 is incorrect. The data provided was the \% of patients with changes during the study and not the \% of patients at the end of the study. The correct table appears below:

Table 2 Responder criteria after 12 weeks of therapy by treatment group

\begin{tabular}{lccc}
\hline & \multicolumn{2}{c}{ Treatment group } & \\
\cline { 2 - 3 } Responder criteria & Placebo $(\mathbf{n}=\mathbf{4 3})$ & Etanercept $(\mathbf{n}=\mathbf{3 9})$ & $\boldsymbol{p}$ value \\
\hline ASAS20 & $14(33 \%)$ & $25(67 \%)$ & 0.003 \\
ASAS40 & $10(23 \%)$ & $17(44 \%)$ & 0.053 \\
ASAS5/6 & $2(5 \%)$ & $8(21 \%)$ & 0.044 \\
ASAS partial remission & $2(5 \%)$ & $7(18 \%)$ & 0.073 \\
BASDAl 50 & $10(23 \%)$ & $18(46 \%)$ & 0.031 \\
ASDAS-CRP changes (W12-baseline) & & & \\
$\quad$ ASDAS $\geq 1.1$ (minimally important & $7(17.1)$ & $25(64.1)$ & $<0.0001$ \\
improvement) & $1(2.4)$ & & \\
$\quad$ ASDAS $\geq 2.0$ (major improvement) & & & \\
ASDAS-CRP status at W12 & $2(4.7 \%)$ & $5(38.5)$ & \\
$\quad$ ASDAS $<1.3$ & $5(11.6 \%)$ & $16(41.0 \%)$ & 0.0001 \\
ASDAS $<2.1$ & & & \\
\hline
\end{tabular}

ASAS = Ankylosing Spondylitis Activity Score; BASDAI = Bath Ankylosing Spondylitis Disease Activity Index, ASDAS = Ankylosing Spondylitis Disease Activity Score 